تأثير المجال المغناطيسي على اداء منقطات الري باستخدام مياه بتراكيز ملحية مختلفة
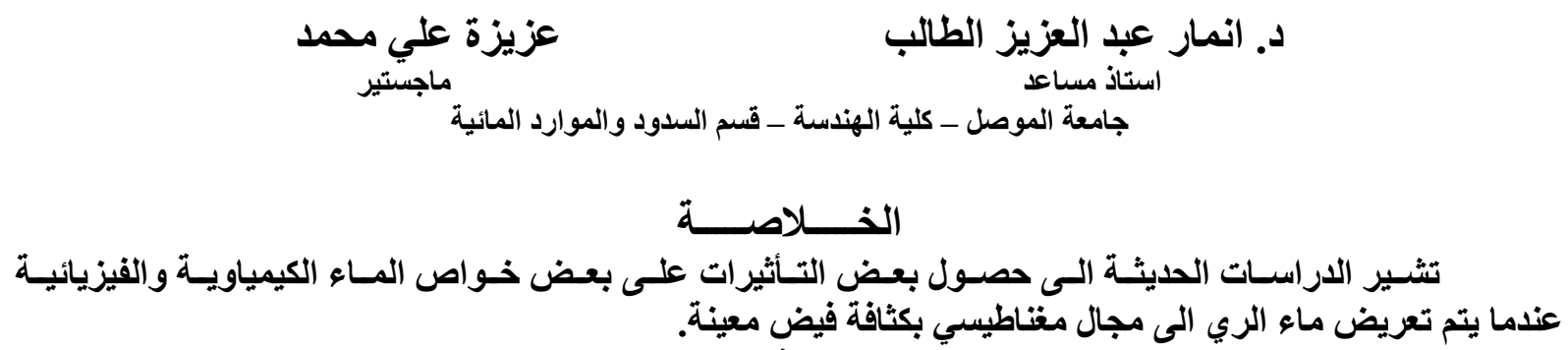

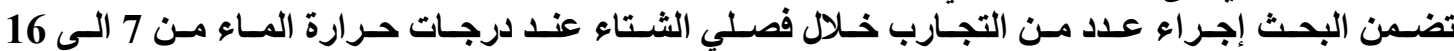

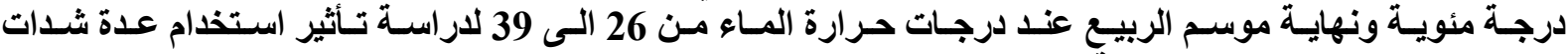

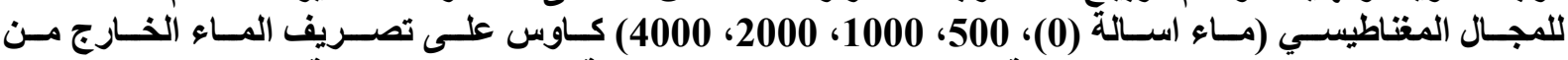

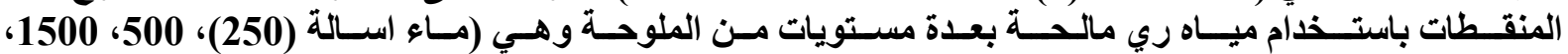

أظهرث النتائج ان هناك تداخل بين تأثير كل من درجة الحرارة والتغيرات المصنعية حالت دون معرفة التأثير 4000) (ملغم/لثر).

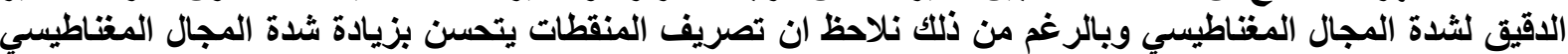
وان تغير درجة الحرارة يؤثز بشكل مباشر على الثئرة التصريف الخارج من المنقطات.

الكلمات المفتاحية: ـالمجال المغناطيسي، المياه المالحة، المياه المعالجة مغناطيسيا

\title{
The Effect Of Magnetic Field On The Performance Of Irrigation Emitters When Using different concentrations of saline water
}

\section{Dr. Anmar A.AL-Talib}

Assistant Professor

\section{Azeza Ali Mohammad \\ M.SC}

\section{Abstract}

Many modern researches indicate the effects on water when it is exposed to magnetic fields that effect some waters chemicals and physical properties.

Paper Included a number of experiments during the winter when the water temperatures of 7 to 16 degrees Celsius and the end of the spring season when water temperatures from 26 to 39 to study the effect of the use of several intensities of magnetic field (water liquefaction (0), 500, 1000, 2000.4000) Kaus to drain the water out of the rasters using saline irrigation water in several levels of salinity which (tap water $(250), 500,1500,4000)(\mathrm{mg} / \mathrm{l})$.

The results showed that there is an overlap between the effect of temperature and workmanship changes prevented without knowing the exact impact of the intensity of the magnetic field and nevertheless note that the discharge of drippers improved to the increasing of the intensity of the magnetic field and temperature change has a direct impact on the outside of the discharge emitters. 


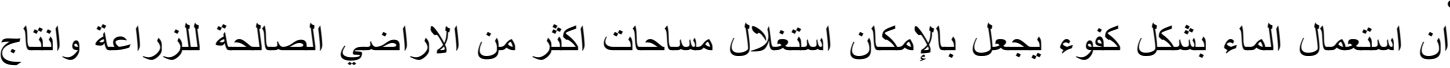

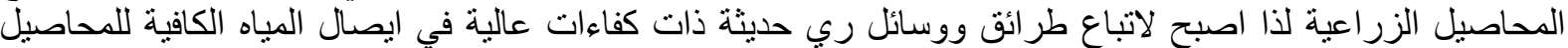

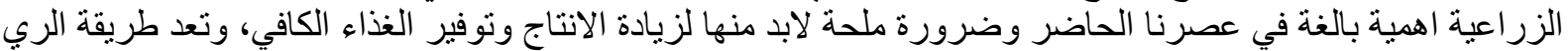

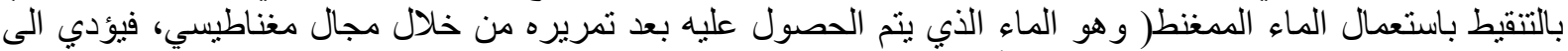

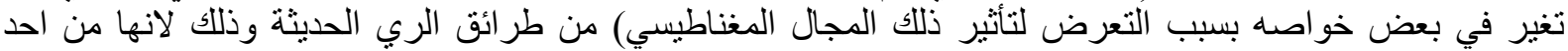

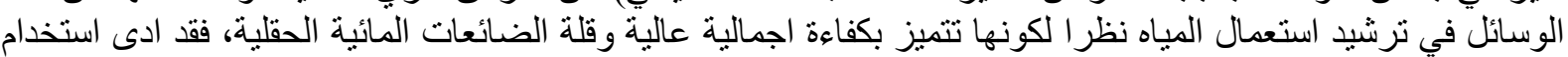

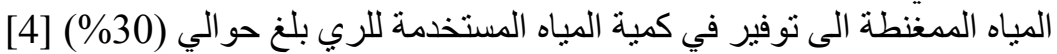

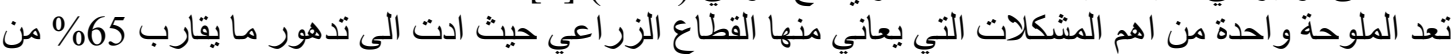

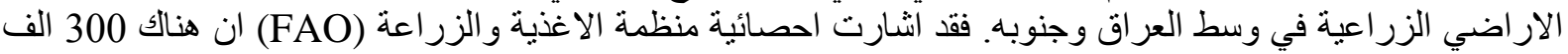

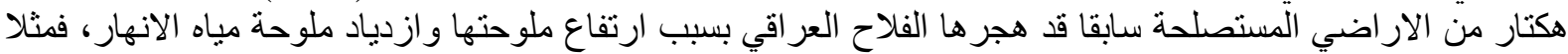

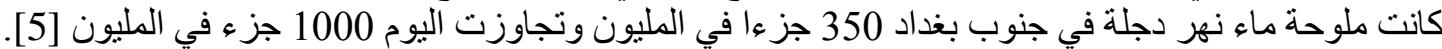

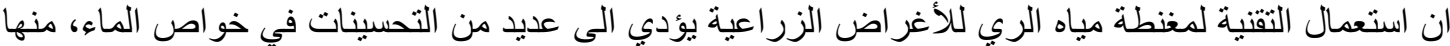

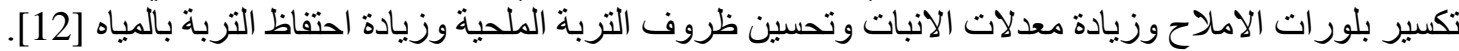

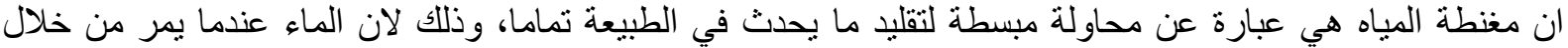

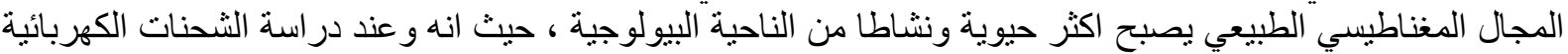

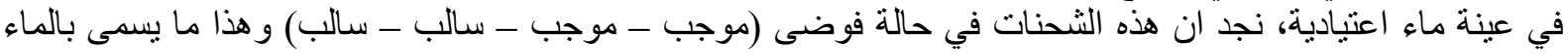

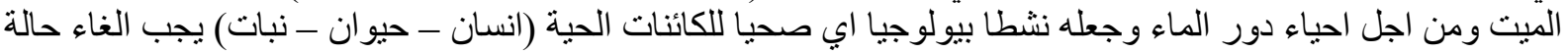

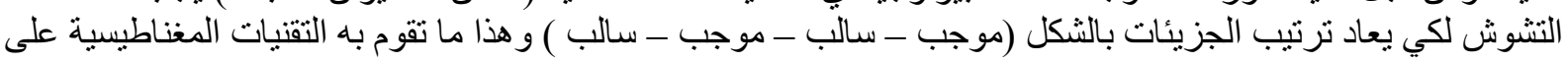
اكمل وجهاه

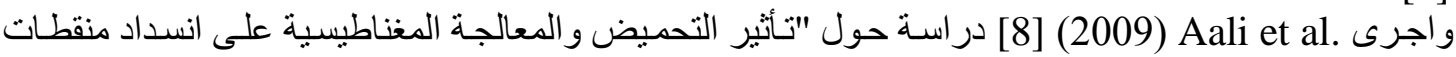

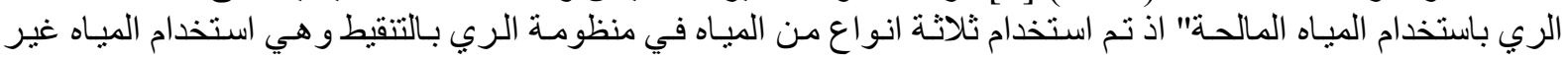

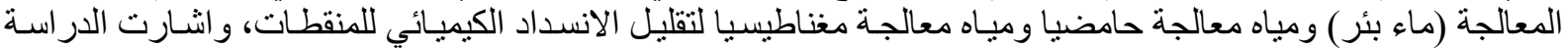

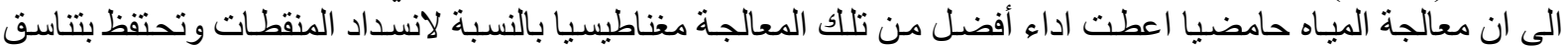

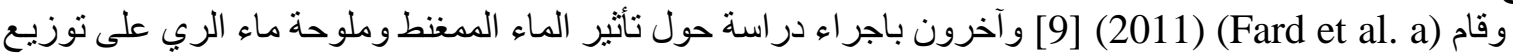

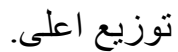

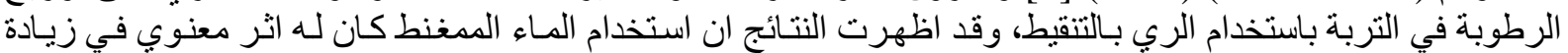
رطوبة التربة بنسبة $7.5 \%$ مقارنة مع التربة الماء العادي.

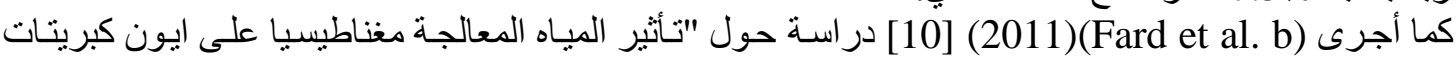

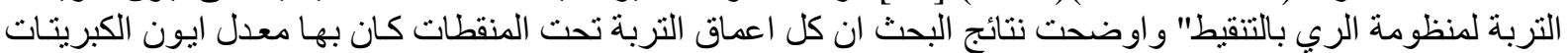

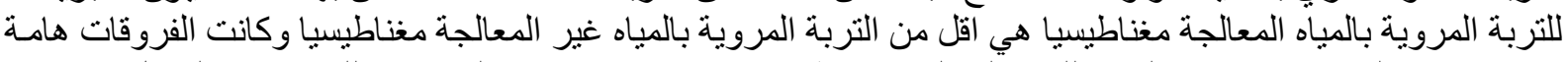

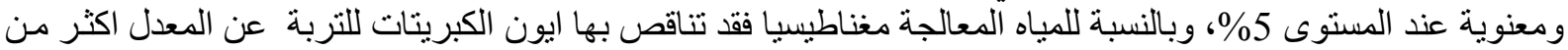

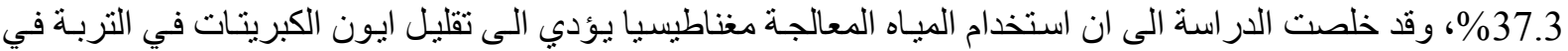
الري بالتنقيط، وهذا يساعد في استصلاح الترب المنملحة .

ان الهدف من البحث هو دراسة تأثير تسليط المجال المغناطيسي على ماء الري المالح المار المار خلال انبوب التنقيط

أهداف البحث:

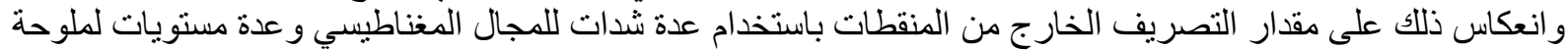

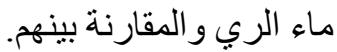

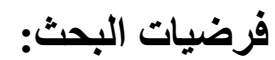
1-تم اعتبار ان التبخر من او عية القياس جميعها متساوي لأنها تمت تحت نفس الظروف وزمن تشغيل واغلاق واحد ولذلك

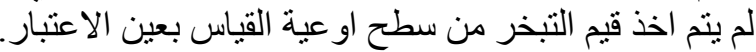
2-تم قياس درجة حر ارة واحدة فقط خلال النهار في أوقات الذروة (الظهيرة) وتم اعتمادها لغرض التصحيح. 


$$
\begin{aligned}
& \text { الأدوات والأجزةة المستخدمة في الاراسة: }
\end{aligned}
$$

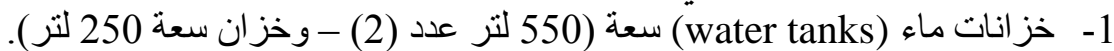

$$
\begin{aligned}
& \text { 2- انابيب مياه بلاستيكية (plastic water pipe) - }
\end{aligned}
$$

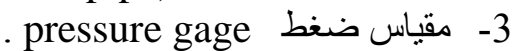

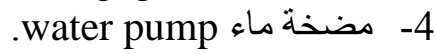

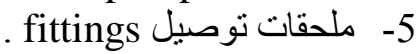

$$
\begin{aligned}
& \text { 6- ابيب تنقيط (laterals) من البولي اثلين بقطر (16 ملم). } \\
& \text { 7- او اوعية قياس (cans) عدن (1a) } 25 \text { (ذو حجم } 32 \text { لتر ). }
\end{aligned}
$$

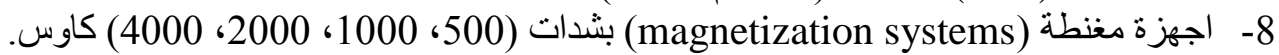

$$
\begin{aligned}
& \text {-9 - - منقطات }
\end{aligned}
$$

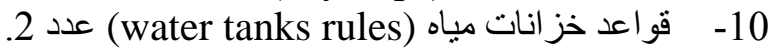

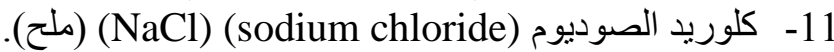

$$
\begin{aligned}
& \text { 12- - 1 - أسطو انة مدرجة لقياس حجم الماء المتجمع في الاوعية. } \\
& \text { 13- ساعة نوقيت. }
\end{aligned}
$$

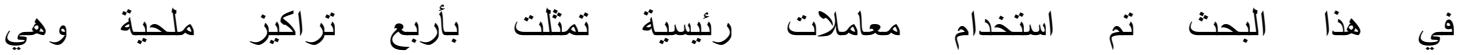

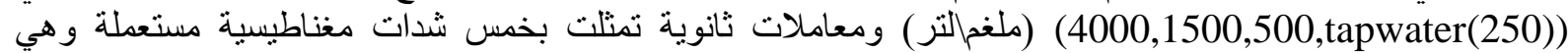
(4000 , 2000 , 1000 , 500 , tap water(0))

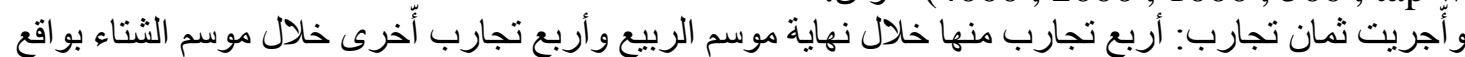

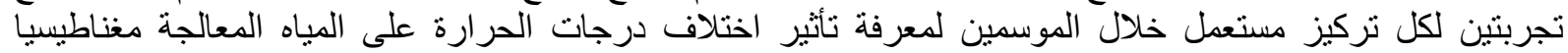

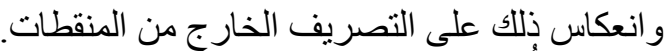

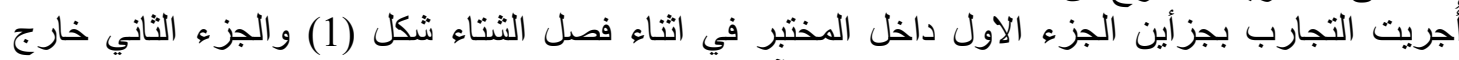

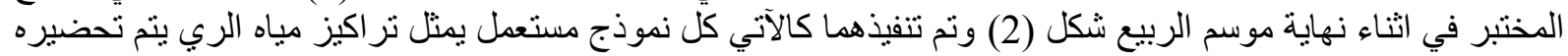

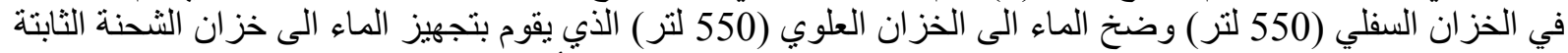

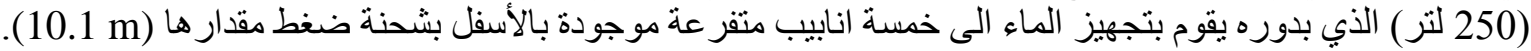

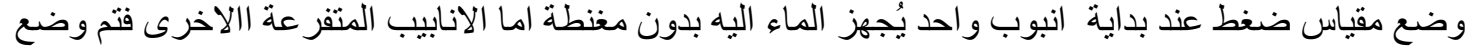

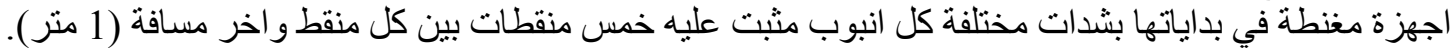

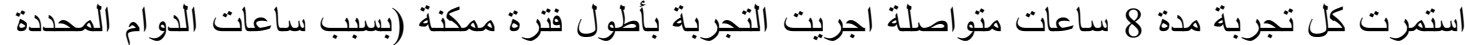

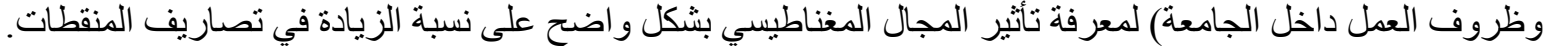

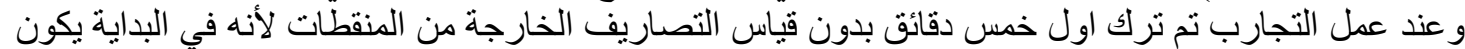

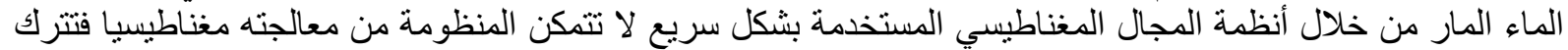
اول خمس دقائق بدون قياس التصاريف الخارجة من المنقطات وبعد ذللك يتم القياس علما بان نهايات انابيب التنقيط تكون

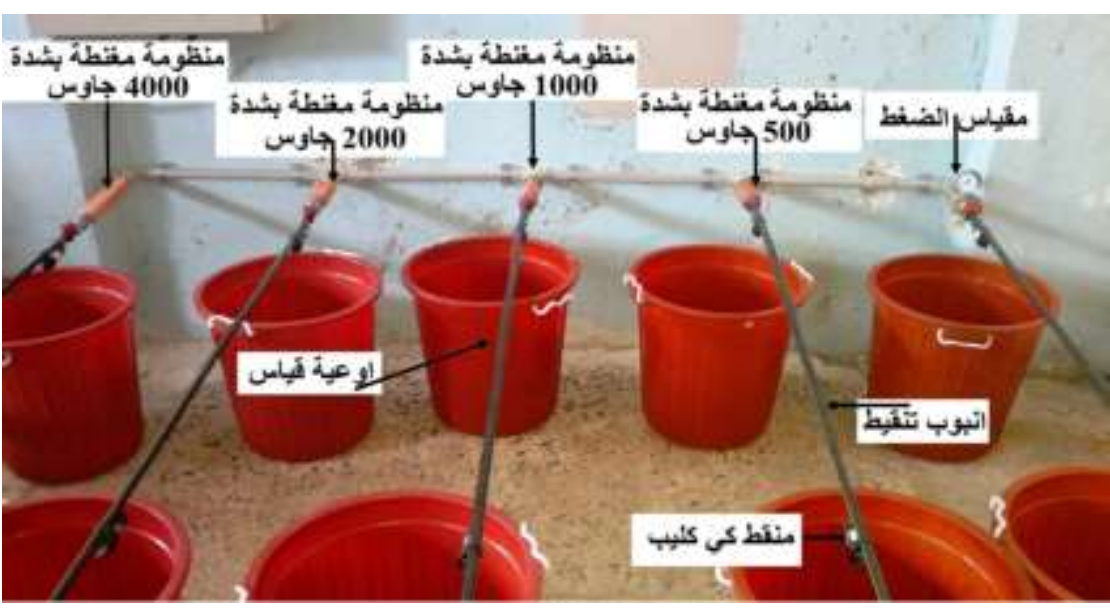

مسدودة تماماً.

الثكل (1) الجزء الاول من التجارب داخل مختبر الهيروليك 


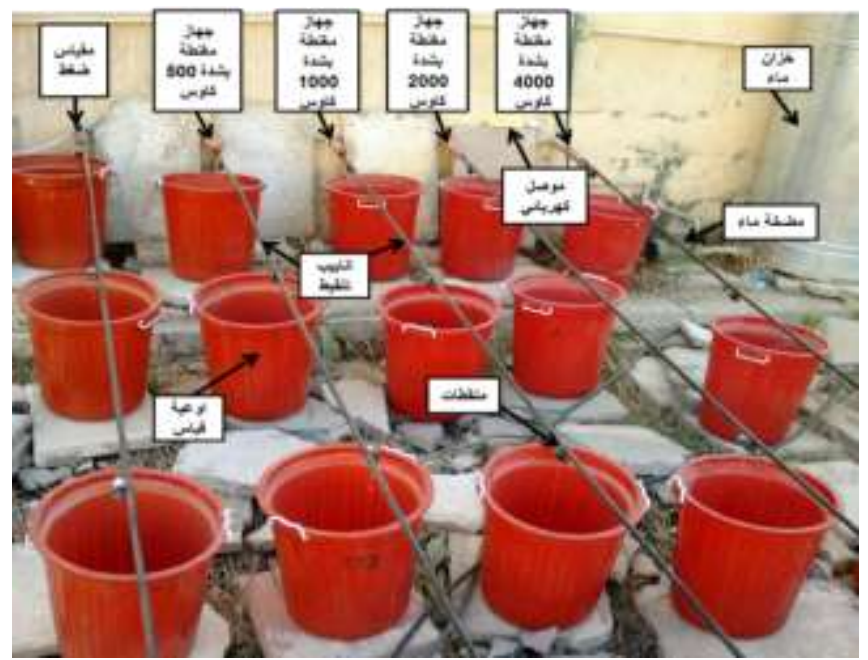

$$
\text { الشكل (2) الجـزء الثاني من التجـارب خارج مختبر الهيدروليك }
$$

المنقطات

$$
\begin{aligned}
& \text { تم استخدام منقطات من نوع "كي كليب" بريطاني الصنع وفيما يلي مواصفات المنقط: } \\
& 4
\end{aligned}
$$

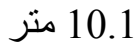

$$
\begin{aligned}
& \text { حلزوني مترن } \\
& 8 \\
& \text { polypropylene } \\
& \text { 1.96=(1.4*1.4) }
\end{aligned}
$$

\section{أجهزة المجال المغناطيسي المستعملة}

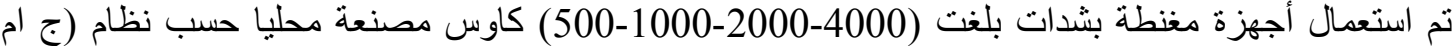
اكس) الأمريكي وشكل (3) يبين أجهزة المغنطة المستعملة في البحث، وقد تم التأكد من شدات المجال المغناطيسي في جامعة الموصل - كلية التربية - قدم الفيزياء.

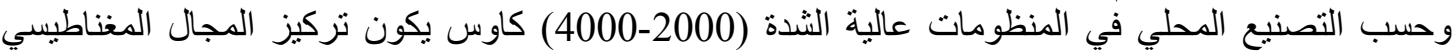

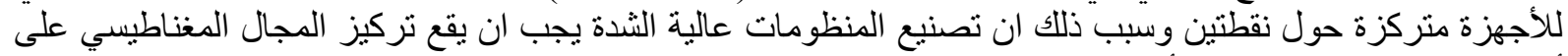

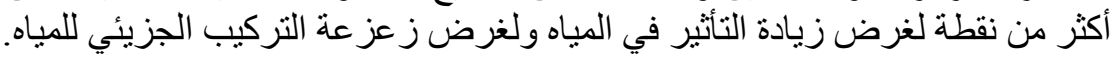

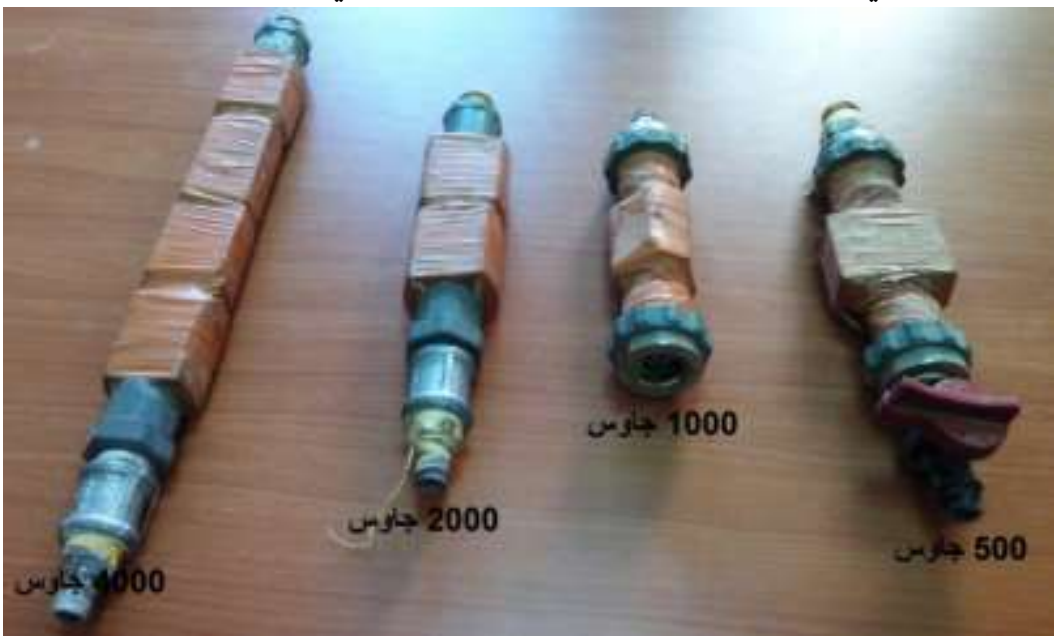

الثكل (3) منظومات المغنطة التي تم استعمالها في التجارب 


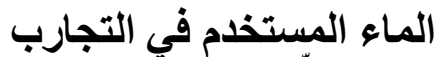

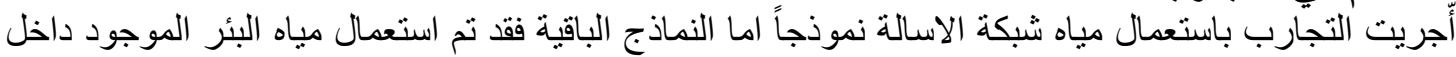

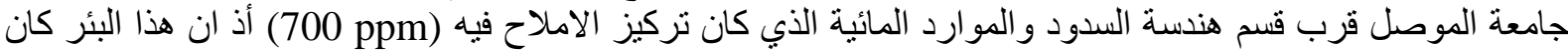

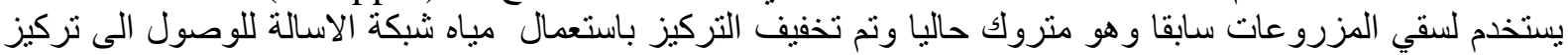

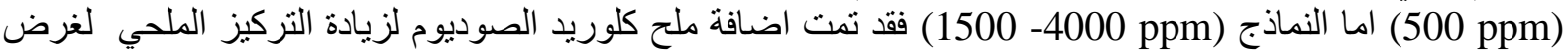

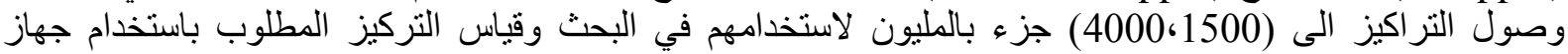

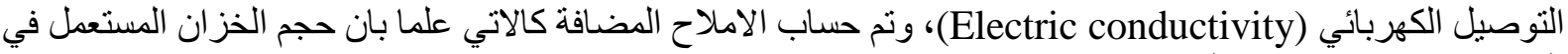

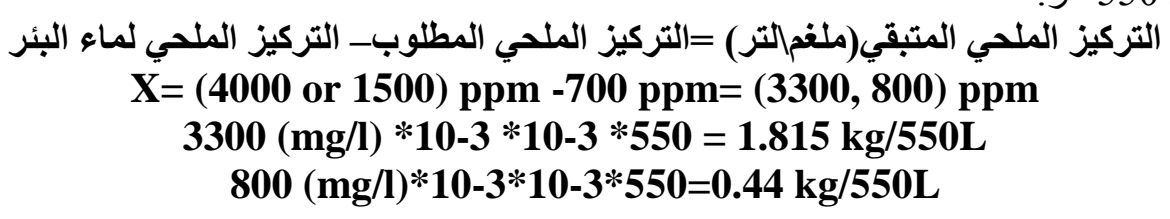

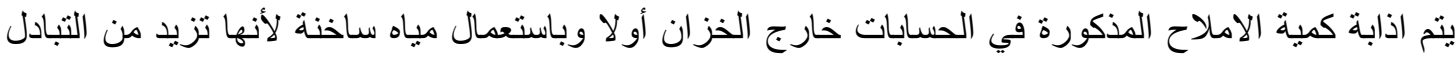

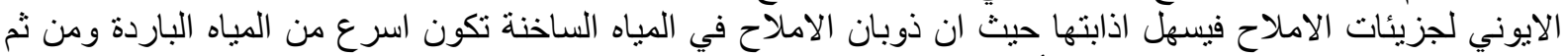

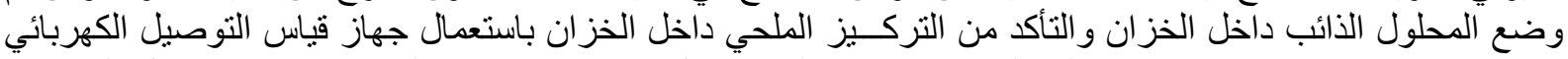

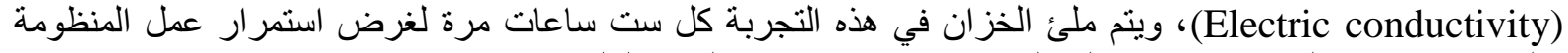
و العلاقة ادناه تبين العلاقة بين الايصالية الكهربائية وكمية الاملاح الذائبة الكلية [6]:

$T D S=0.64 E C$

$$
\text { حيث: EC = TDS= الايصالية الاملاح الذهربية الكلية (ملغم التر) }
$$

ولكل تجربة يتم عملها ينم غسل المنظومة لغرض عدم تر اكم الاملاح وبالتالي التأثير على التصاريف الخارجة

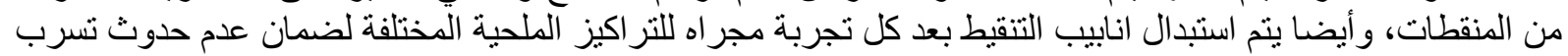

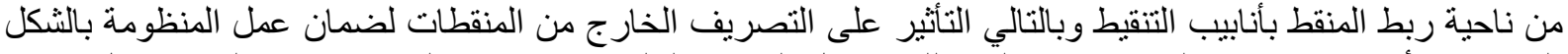

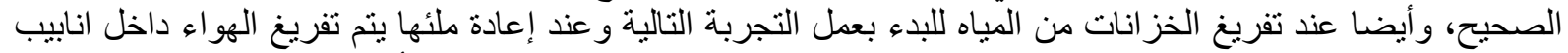

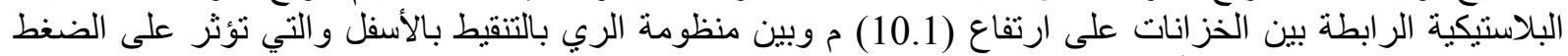
التشغيلي المطلوب و بالتالي التأثير على التصريف الخارج من المنقطات وييين شكل (4) الادوات المستعملة في البحث.

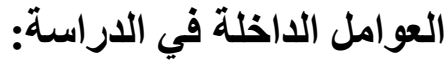 اولا: تقييم منقطات الري: الرئ}

تعدُ منقطات الري (emitters) من اهم اجزاء شبكة الري بالتنقيط حيث تتم بو اسطتها اضافة الماء للنبات بمعدل

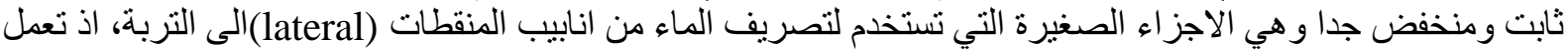

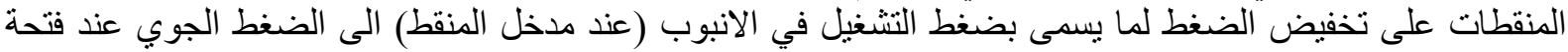

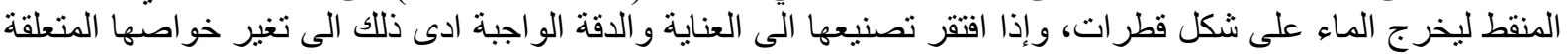

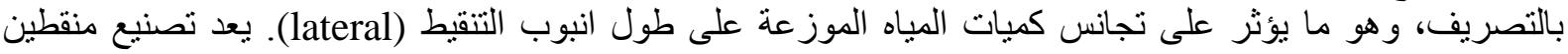

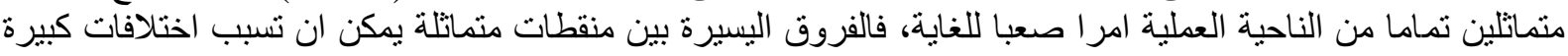

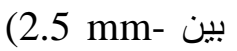

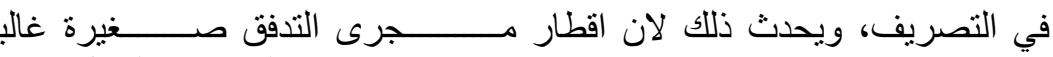

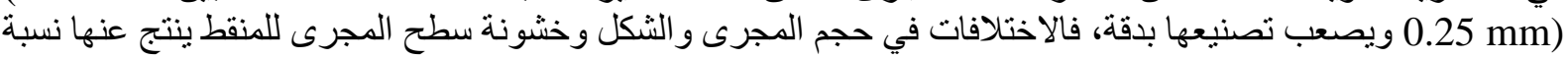
مئوية كبيرة في اختلاف مقاسات المنقط، ويعتمد حجم الفروقات على تصميم المنقط والمواد المستخدمة للصنع ثم دقة يستخدم معامل تغير صناعة المنقط كمقياس للتغير ات او الاختلافات المنوقعة في تصريف المنقطات ويحسب هذا التصنيع.

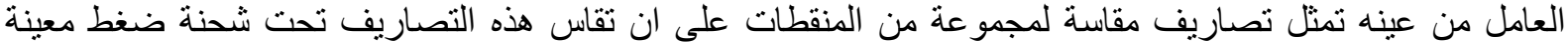
ومناسبة لللك المنقط، وبعامة يمكن تصنيف تغير صنع المنقطات حسب معامل التغير (CV) على الوجه التنالي [3] : 


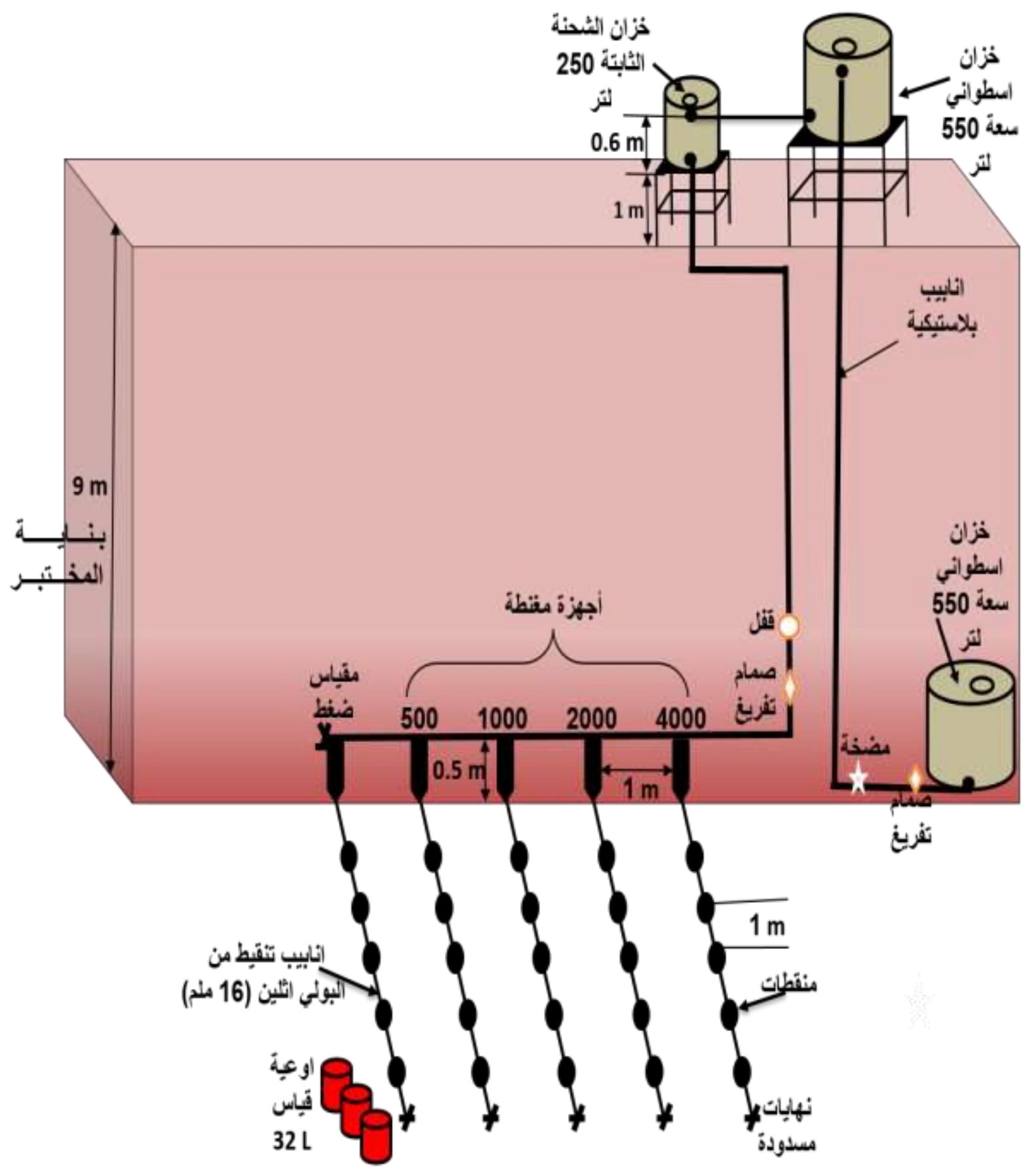

$$
\text { الثكل (4) مخطط يبين اجزاء التجرية }
$$


الطالب: تأثير المجال المغناطيسي على اداء منقطات الري باستخدام مياه بتراكيز ملحية مختلفة

\begin{tabular}{|c|c|}
\hline \multicolumn{2}{|c|}{ الجدول (1) بيان حالة المنقط على ضو ه قيمة معامل الاختلاف المصنعي (CV) } \\
\hline معامل الاختلاف المصنعي & كفاءة المنقط \\
\hline $\mathrm{CV} \leq 0.05$ & ممتاز \\
\hline $0.05<\mathrm{CV} \leq 0.07$ & متوسط \\
\hline $0.07<\mathrm{CV} \leq 0.11$ & 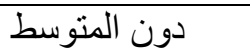 \\
\hline $0.11<\mathrm{CV} \leq 0.15$ & رديء \\
\hline $0.15<\mathrm{CV}$ & 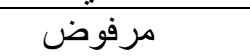 \\
\hline
\end{tabular}

$\mathrm{Cv}=\frac{\mathrm{Sd}}{\mathrm{qa}}$
$\mathrm{Sd}=\sqrt{\frac{\mathrm{q}^{2}+\mathrm{q}^{2}+\cdots+\mathrm{qn}^{2}-\mathrm{nqa}^{2}}{\mathrm{n}-1}}$

ويحسب معامل الاختلاف المصنعي من العلاقة:

$$
\begin{aligned}
& \text { حيث ان: - }
\end{aligned}
$$

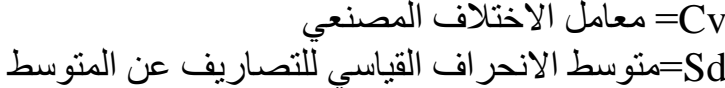

$$
\begin{aligned}
& \text { qa }
\end{aligned}
$$

تمت معايرة منقطات الري نوع (كي كليب ذو مسار طويل) و هو بريطاني الصنع بتصريف تصميمي مقداره 4 نوان

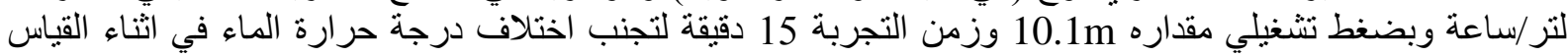

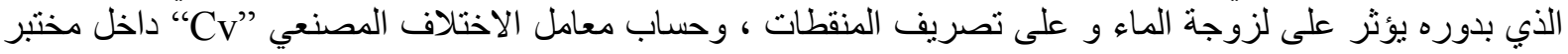

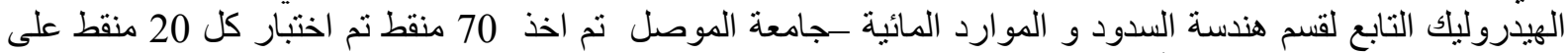

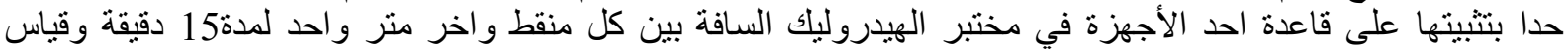
التصريف المتجمع لكل منقط وكما مبين في الثكل (5) وتم اختيار 25 منقط من بين 70 منقط على اساس انها تعطي اقل نسبة لمعامل الاختلاف المصنعي وكانت النسبة هي 1.14\%.

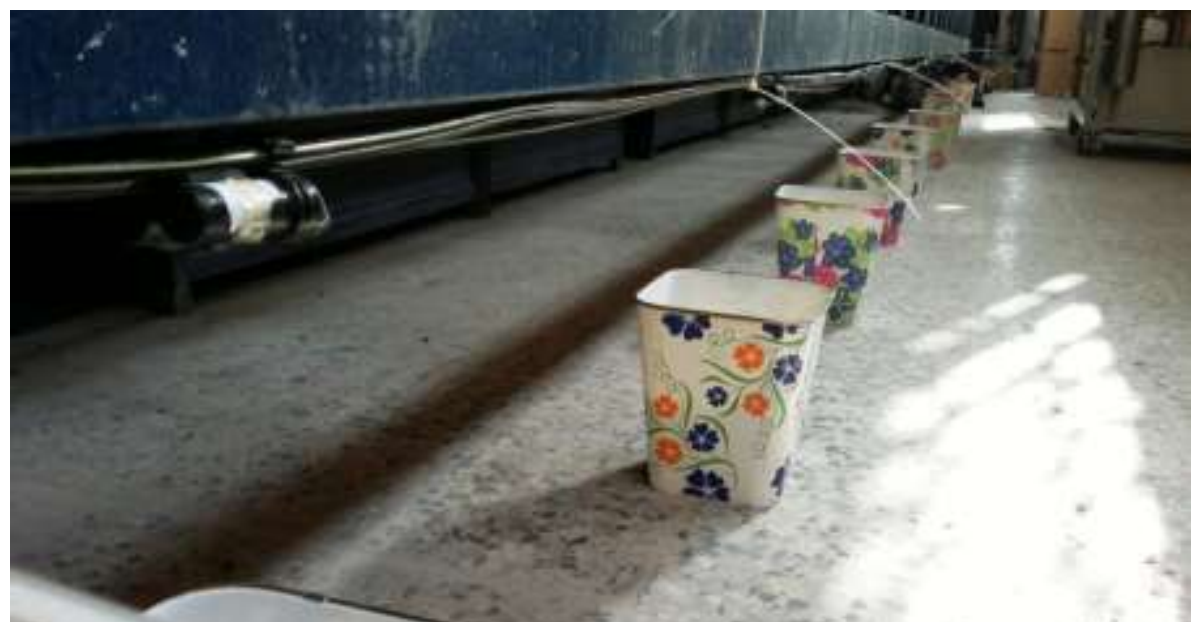

\section{الشكل (5) تقييم معامل الاختلاف المصنعى}

\subsection{3}

تتعرض المنقطات الموجودة في الحقول المفتوحة الى درجات درجات حرارة متباينة خلال اليوم الواحد بين الليل و النهار

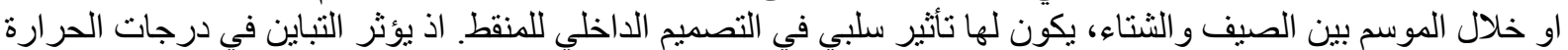

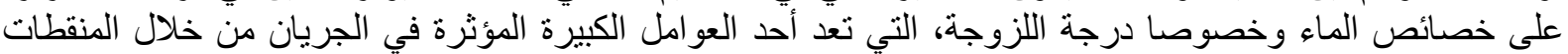

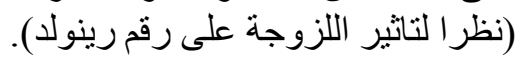
وللأغر اض التطبيقية والتصميمية، يمكن وصف التيفية الاداء الهيدروليكي للمنقط من خلال علاقة تجريبية تربط بين التصريف $\mathrm{q}=\mathrm{kh} \mathrm{h}^{\mathrm{x}}$

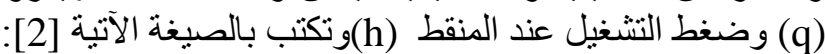


تمثل k و و ثو ابت ويمكن ايجادها من المعادلات التجريبية عند ظروف ثابتة. كما يعبر الثابت x عن خصائص

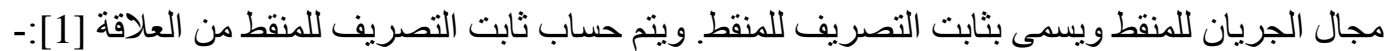

$X=\frac{\log \left(\frac{q 1}{q 2}\right)}{\log \left(\frac{H 1}{H 2}\right)}=\frac{\log \left(\frac{410}{290}\right)}{\log \left(\frac{6}{4}\right)}=0.85$

حيث ان q1\&q2 هما التصريف للمنقط عند ضغطي التتغيل H1 \& H2 بالترتيب.

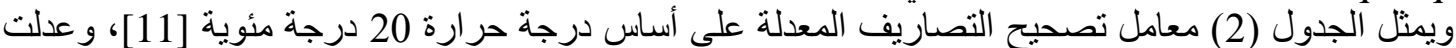

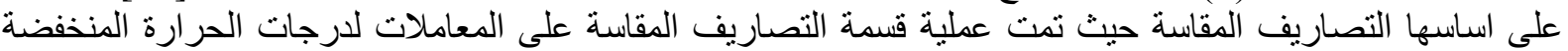

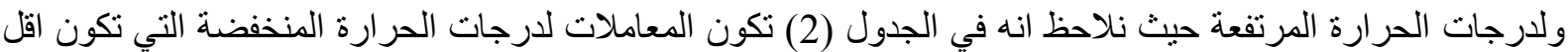

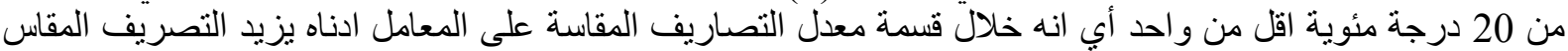

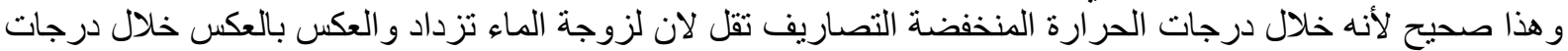

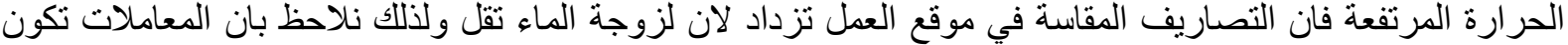

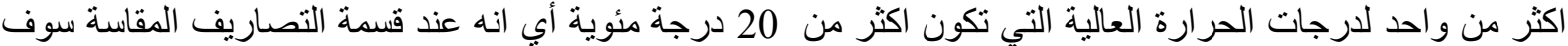

\begin{tabular}{|c|c|c|c|c|c|c|c|}
\hline \multicolumn{8}{|c|}{ الجدول (2) معامل تصحيح التصاريف للمنقط نو ع كي كليب (ذو مسئر طويل) بدليل التصريف X=0.85 عند درجة } \\
\hline Temperature & $X=1.00$ & $X=0.85$ & $X=0.8$ & Temperature & $X=1.00$ & $X=0.85$ & $X=0.8$ \\
\hline 10 & 0.75 & 0.8775 & 0.92 & 26 & 1.16 & 1.085 & 1.06 \\
\hline 11 & 0.774 & 0.888 & 0.926 & 27 & 1.19 & 1.1 & 1.07 \\
\hline 12 & 0.798 & 0.8985 & 0.932 & 28 & 1.22 & 1.115 & 1.08 \\
\hline 13 & 0.822 & 0.909 & 0.938 & 29 & 1.25 & 1.13 & 1.09 \\
\hline 14 & 0.846 & 0.9195 & 0.944 & 30 & 1.28 & 1.145 & 1.1 \\
\hline 15 & 0.87 & 0.93 & 0.95 & 31 & 1.31 & 1.1585 & 1.108 \\
\hline 16 & 0.896 & 0.944 & 0.96 & 32 & 1.34 & 1.172 & 1.116 \\
\hline 17 & 0.922 & 0.958 & 0.97 & 33 & 1.37 & 1.1855 & 1.124 \\
\hline 18 & 0.948 & 0.972 & 0.98 & 34 & 1.4 & 1.199 & 1.132 \\
\hline 19 & 0.974 & 0.986 & 0.99 & 35 & 1.43 & 1.2125 & 1.14 \\
\hline 20 & 1 & 1 & 1 & 36 & 1.456 & 1.2265 & 1.15 \\
\hline 21 & 1.026 & 1.014 & 1.01 & 37 & 1.482 & 1.2405 & 1.16 \\
\hline 22 & 1.052 & 1.028 & 1.02 & 38 & 1.508 & 1.2545 & 1.17 \\
\hline 23 & 1.078 & 1.042 & 1.03 & 39 & 1.534 & 1.2685 & 1.18 \\
\hline 24 & 1.104 & 1.056 & 1.04 & 40 & 1.56 & 1.2825 & 1.19 \\
\hline 25 & 1.13 & 1.07 & 1.05 & & & & \\
\hline
\end{tabular}

النتائج والمناقشة

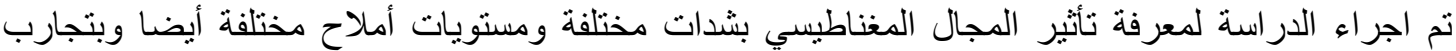

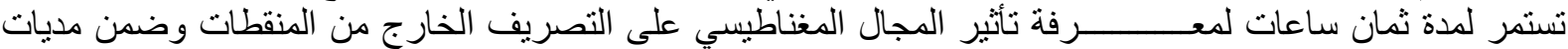

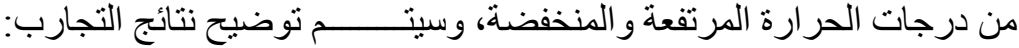

تأثير شدات المجال المغناطيسي:

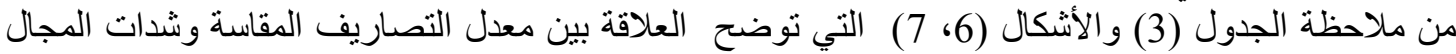

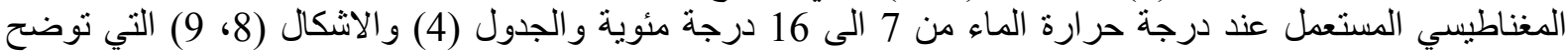

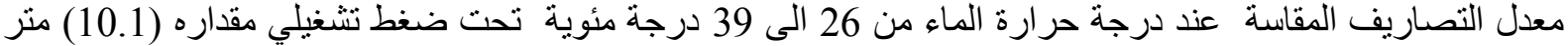

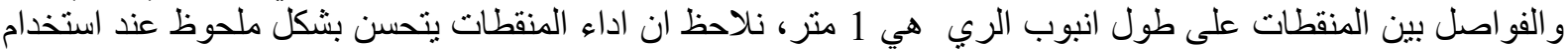

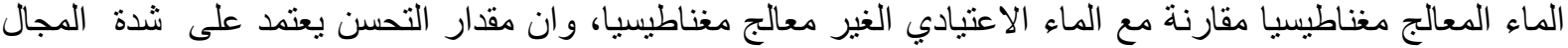

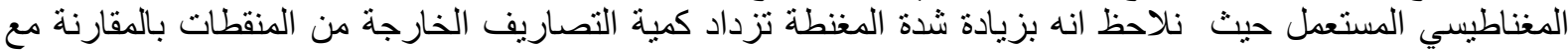

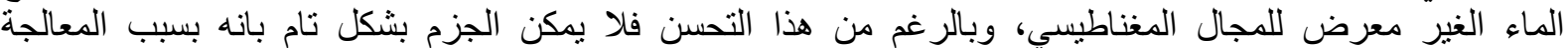


الطالب: تأثير المجال المغناطيسي على اداء منقطات الري باستخدام مياه بتراكيز ملحية مختلفة

المغناطيسية لان هناك تداخل بين تأثثير كل من درجة الحرارة والتغيرات الدصنعية حالت دون معرفة التأثير الدقيق لكل شدة من شدات المجال المغناطيسي المستعملة.

\begin{tabular}{|c|c|c|c|c|c|c|c|c|c|c|}
\hline \multicolumn{11}{|c|}{ 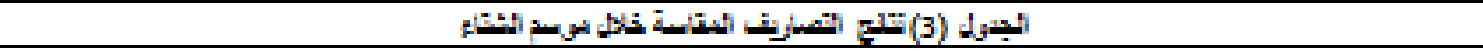 } \\
\hline \multirow{2}{*}{\multicolumn{6}{|c|}{ 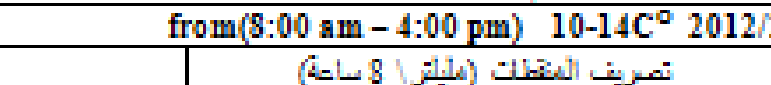 }} & \multirow[b]{3}{*}{ التصنيف: } & \multirow[b]{3}{*}{ التمبريخ } & \multirow{3}{*}{ 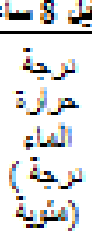 } & \multirow{3}{*}{ 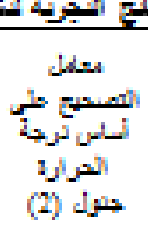 } & \multirow{3}{*}{ 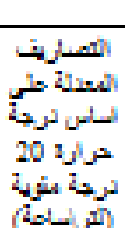 } \\
\hline & & & & & & & & & & \\
\hline المشتة المبجدي & 1 & 2 & 3 & 4 & 5 & & & & & \\
\hline 0 & 22400 & 22930 & 23080 & 23600 & 22800 & 2962 & 2.870 & 14 & 0.9195 & \\
\hline 500 & 23170 & 22820 & 228550 & 23320 & 23000 & 23032 & 2.879 & 14 & 0.9195 & \\
\hline 1000 & 23000 & 23000 & 23100 & 22760 & 23340 & 23040 & 2.880 & 14 & 0.9195 & 3.132 \\
\hline 2000 & 22330 & 23240 & 24000 & 23400 & 23000 & 3194 & 2.899 & 14 & 0.9195 & 3.153 \\
\hline 4000 & 22680 & 23400 & 23820 & 23510 & 23800 & 23442 & 2.930 & 14 & 0.9195 & 3.187 \\
\hline \multicolumn{11}{|c|}{ 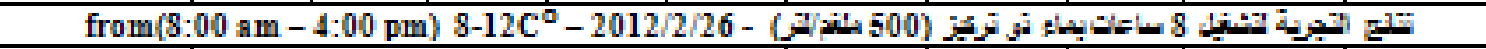 } \\
\hline \multirow[b]{2}{*}{ 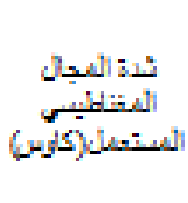 } & \multicolumn{5}{|c|}{ 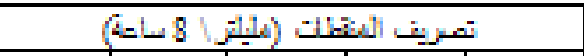 } & \multirow[b]{2}{*}{ التصنيفل } & \multirow[b]{2}{*}{ التمبريخ } & \multirow{2}{*}{ لرزبة } & \multirow[b]{2}{*}{ 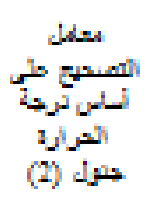 } & \multirow{2}{*}{ 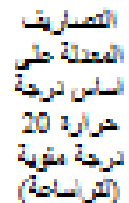 } \\
\hline & 1 & 2 & 3 & 4 & 5 & & & & & \\
\hline 0 & 22340 & 22220 & 22600 & 21900 & 22000 & 224 & 2.778 & 12 & 0.8985 & 3.092 \\
\hline 500 & 22320 & 22450 & 23050 & 22400 & 22340 & 22512 & 2.814 & 12 & 0.8985 & 3.132 \\
\hline 1000 & 22380 & 22320 & 23650 & 22420 & 22440 & 22642 & 2.830 & 12 & 0.8985 & 3.150 \\
\hline 2000 & 22520 & 22760 & 23720 & 22740 & 22460 & 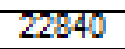 & 2.855 & 12 & 0.8985 & 3.178 \\
\hline 4000 & 22550 & 22820 & 23700 & 22500 & 22600 & 22846 & 2.856 & 12 & 0.8985 & 3.178 \\
\hline \multicolumn{11}{|c|}{ 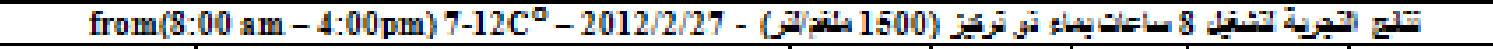 } \\
\hline \multirow[b]{2}{*}{ 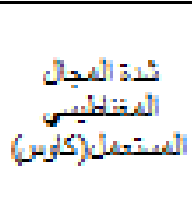 } & \multicolumn{5}{|c|}{ 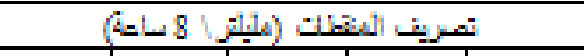 } & \multirow[b]{2}{*}{ التمبريف } & \multirow[b]{2}{*}{ التمريف } & \multirow{2}{*}{ 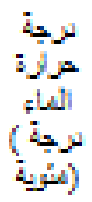 } & \multirow[b]{2}{*}{ 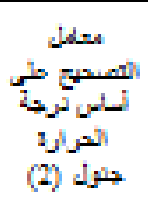 } & \multirow{2}{*}{ 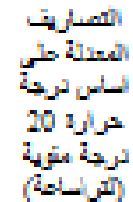 } \\
\hline & 1 & 2 & 3 & 4 & 5 & & & & & \\
\hline 0 & 22200 & 21520 & 22220 & 22000 & 21520 & 21892 & 2.737 & 12 & 0.8985 & 3.046 \\
\hline 500 & 22000 & 222000 & 22640 & 22200 & 21800 & 22248 & 2.781 & 12 & 0.8985 & 3.095 \\
\hline 1000 & 22430 & 22440 & 22650 & 22500 & 22000 & 404 & 801 & 12 & 0.8985 & 3.117 \\
\hline 2000 & 22480 & 222680 & 23020 & 22640 & 22000 & 64 & 821 & 12 & 0.8985 & 3.1 \\
\hline 4000 & 22640 & 22700 & 22840 & 22600 & 22440 & 22644 & 2.831 & 12 & 0.8985 & 3.150 \\
\hline \multicolumn{11}{|c|}{ 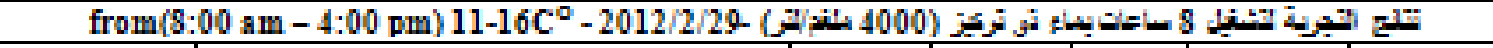 } \\
\hline \multirow[b]{2}{*}{ 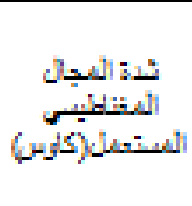 } & & $4=8$ & ئت (ملبلتر & عزيف اله: & & & & & Es & \\
\hline & 1 & 2 & 3 & 4 & 5 & التصنيفيف) & التمريف & لرنسئة & 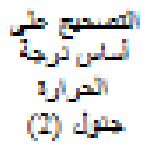 & 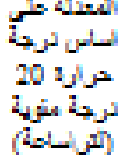 \\
\hline 0 & 23430 & 23300 & 24000 & 23100 & 22300 & 23250 & 2.905 & 16 & 0.944 & 3.079 \\
\hline 500 & 23300 & 24040 & 24100 & 23450 & 22600 & 23510 & 2.939 & 16 & 0.944 & 3.113 \\
\hline 1000 & 23800 & 24000 & 24210 & 23500 & 22900 & 23694 & 2.962 & 16 & 0.944 & 3.137 \\
\hline 2000 & 24000 & 24080 & 25000 & 23600 & 23280 & 23992 & 2.599 & 16 & 0.944 & 3.177 \\
\hline 4000 & 24080 & 24380 & 24820 & 24000 & 23750 & 24202 & 3.025 & 16 & 0.944 & .205 \\
\hline
\end{tabular}




\begin{tabular}{|c|c|c|c|c|c|c|c|c|c|c|}
\hline \multicolumn{11}{|c|}{ 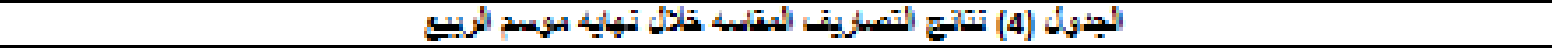 } \\
\hline \multicolumn{6}{|c|}{ from $(8: 00 \mathrm{am}-4: 00 \mathrm{pm}) 28-36 \mathrm{C}^{\circ} \quad 2012 /$} & \multirow{3}{*}{ التصرين } & \multirow{3}{*}{ التصرين } & .8 & - & \\
\hline \multirow{2}{*}{ الندة الفجبل } & \multicolumn{5}{|c|}{ 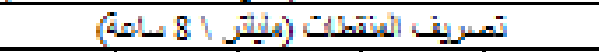 } & & & \multirow{2}{*}{ 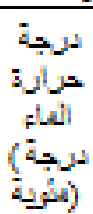 } & \multirow{2}{*}{ 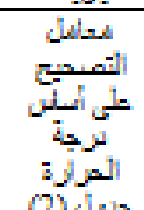 } & \multirow{2}{*}{ 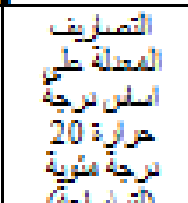 } \\
\hline & 1 & 2 & 3 & 4 & 5 & & & & & \\
\hline 0 & 27090 & 27730 & 27080 & 27380 & 28100 & 27476 & 3.4345 & 36 & $\frac{1.250}{1.2265}$ & 000 \\
\hline 500 & 27170 & 27420 & 27650 & 27320 & 28000 & 27512 & 3.439 & 36 & 1.2265 & \\
\hline 1000 & 27000 & 27300 & 27600 & 27760 & 28000 & 27532 & 3.4415 & 36 & 1.2265 & $\overline{06}$ \\
\hline 2000 & 27530 & 27240 & 28000 & 27800 & $27 \%$ & 27534 & 3.44175 & 36 & 1.2265 & 2.806 \\
\hline 4000 & 27680 & 27400 & 27820 & $277 \% 0$ & 27320 & 27586 & 3.44825 & 36 & 1.2 & 71 \\
\hline \multirow{2}{*}{\multicolumn{6}{|c|}{ 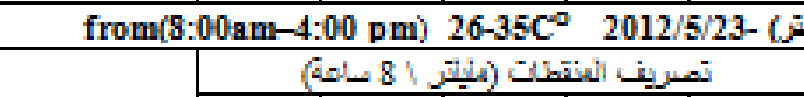 }} & 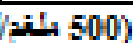 & لم لماع أو تركيز & سنتات & يتة التي & 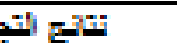 \\
\hline & & & & & & \multirow[b]{2}{*}{ التصنيفن } & \multirow[b]{2}{*}{ التصرين } & \multirow{2}{*}{ لدرجة } & \multirow{2}{*}{ 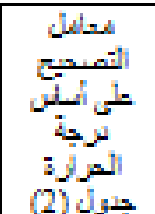 } & \multirow{2}{*}{ 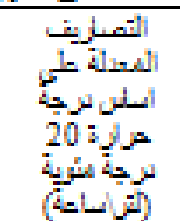 } \\
\hline 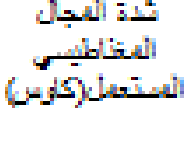 & 1 & 2 & 3 & 4 & 5 & & & & & \\
\hline 0 & 27000 & 27120 & 27900 & 28150 & 27750 & 27584 & 3.448 & 35 & & \\
\hline 500 & 27130 & 27400 & 27450 & 27525 & 28525 & 27606 & 3.451 & 35 & 1.2 & \\
\hline 1000 & 27400 & 26375 & 27450 & 28100 & 28720 & 27609 & 3.451 & 35 & 1.2125 & 2.846 \\
\hline 2000 & 27460 & 27200 & 27750 & 28030 & 27975 & 27683 & 3.460 & 35 & 1.2125 & 2.854 \\
\hline 4000 & 27000 & 27800 & 27450 & 28250 & 28100 & 27720 & 3.465 & 35 & 1.2125 & 58 \\
\hline \multirow{2}{*}{\multicolumn{6}{|c|}{\begin{tabular}{l|r|c|c|}
\multicolumn{2}{|c|}{ from(8:00am-4:00pm) $31-38 \mathrm{C}^{-}-2012 / 5 / 28$} \\
\end{tabular}}} & \multirow[b]{3}{*}{ التصنيفن } & \multirow{3}{*}{ 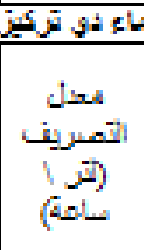 } & \multirow{3}{*}{ لرجائة } & \multirow{3}{*}{ 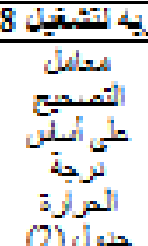 } & \multirow{3}{*}{ 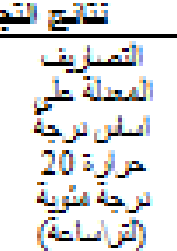 } \\
\hline & & & & & & & & & & \\
\hline 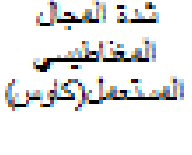 & 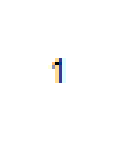 & 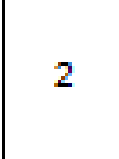 & 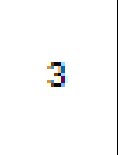 & 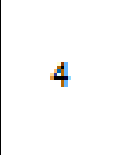 & 5 & & & & & \\
\hline 0 & 28090 & 28200 & 29020 & $28 / 20$ & 27890 & 28504 & 3.563 & 38 & 1.2545 & 2.840 \\
\hline 500 & 28780 & 28540 & 29400 & 27180 & 29370 & 28654 & 3.582 & 38 & 1.2545 & 2.855 \\
\hline 1000 & 28940 & 27900 & 28930 & 28810 & 29140 & 28744 & 3.593 & 38 & 1.2545 & 2.864 \\
\hline 2000 & 28080 & 28480 & 29130 & 29800 & 28800 & 28858 & 3.607 & 38 & 1.2545 & 2.875 \\
\hline 4000 & 21800 & 28900 & 28590 & 29230 & 29850 & 28898 & 3.612 & 38 & 1.2545 & $2.8 / 9$ \\
\hline \multicolumn{11}{|c|}{ 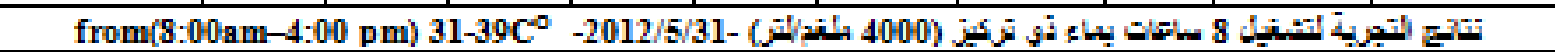 } \\
\hline \multirow[b]{2}{*}{ النشئ العجبال } & \multicolumn{5}{|c|}{ 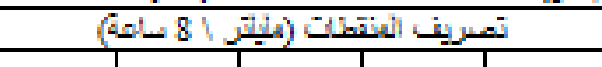 } & \multirow[b]{2}{*}{ التصريف } & \multirow[b]{2}{*}{ |تصنيف } & لدرجة & & \\
\hline & 1 & 2 & 3 & 4 & 5 & & & دالفئة & & \\
\hline 0 & 28130 & 28790 & 28530 & 28700 & 28320 & 28494 & 3.5 & 39 & 1.2685 & 2.8078439 \\
\hline 500 & 28520 & 28220 & 28300 & 28330 & 29500 & 28594 & 3.574 & 39 & 1.2685 & 2.8176981 \\
\hline 1000 & 28880 & 28000 & 28700 & 29050 & 29320 & 28790 & 3.599 & 39 & 1.2685 & 2.8370122 \\
\hline 2000 & 28510 & 28410 & 28930 & 29340 & 28950 & 28848 & 3.606 & 39 & 1.2685 & 2.8427276 \\
\hline 4000 & 28180 & 29280 & 28900 & 29350 & 28840 & 28912 & 3.614 & 39 & 1.2685 & 2.8490343 \\
\hline
\end{tabular}


الطلب: تأثير المجال المغناطيسي على اداء منقطات الري باستخدام مياه بتراكيز ملحية مختلفة
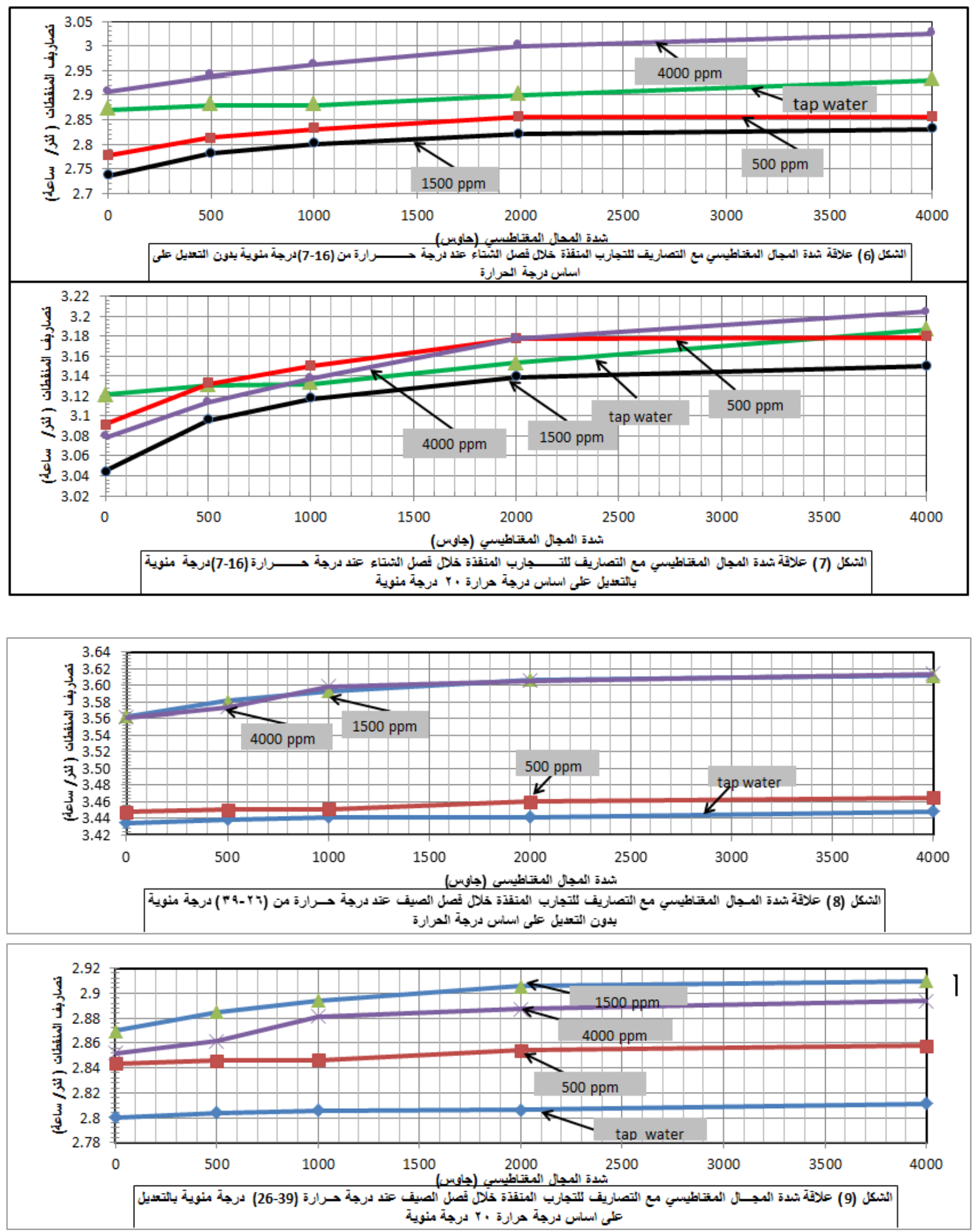


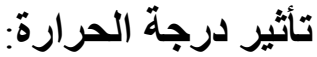

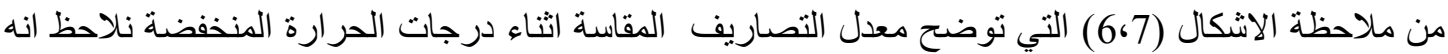

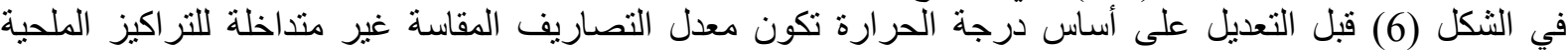

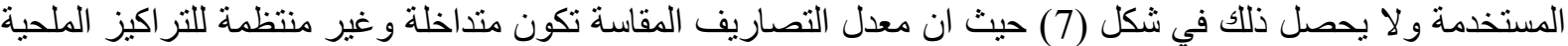

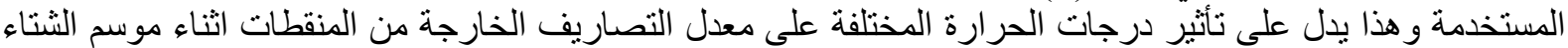

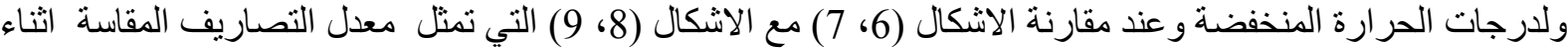

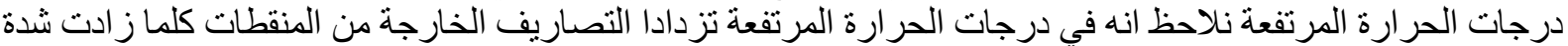

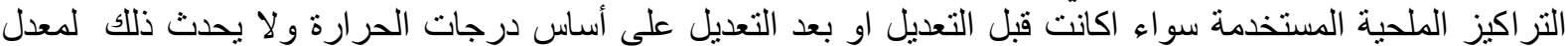

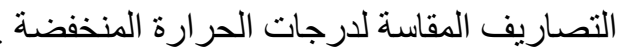

تأثير التراكيز الملحية المستخدمة:

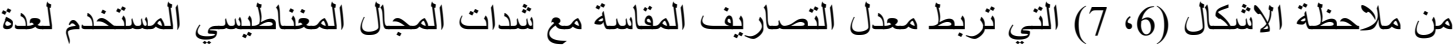

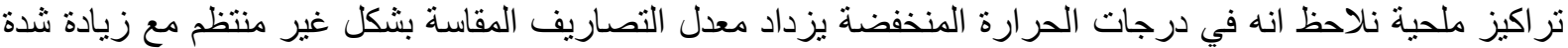

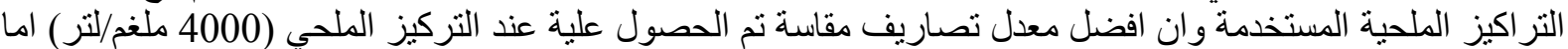

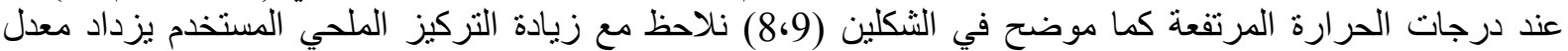

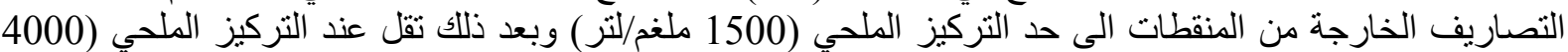

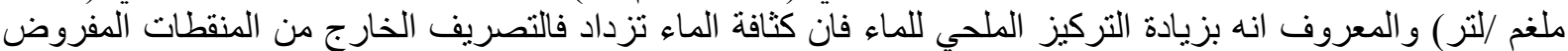

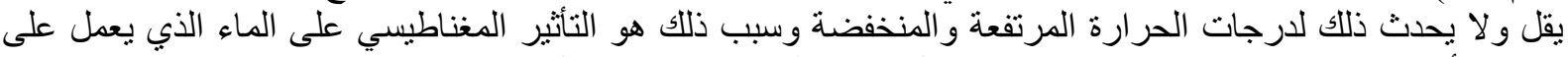

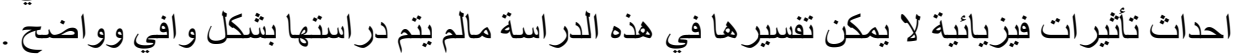
التحليل الافقي للبيانات المقاسة:

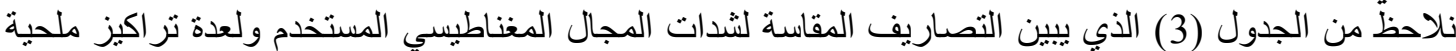

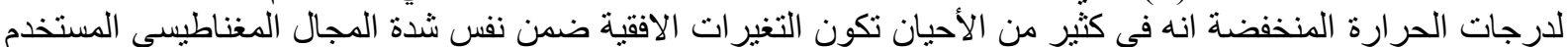

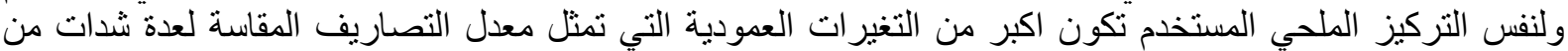

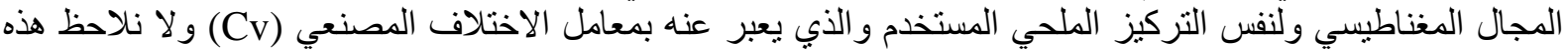

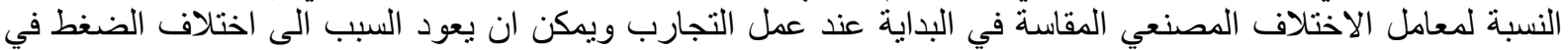

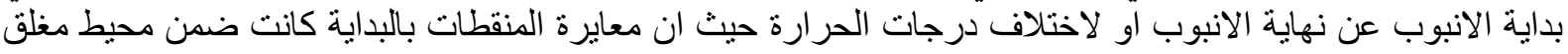

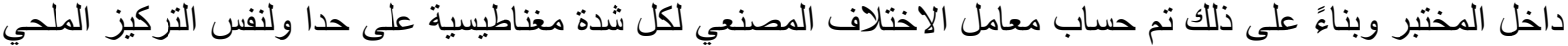
ولجزأي البحث الذي تم اجراه ويبين جدول(5) نسب معامل الاختلاف المصنعي لجزأي البحث ولم تتجاوز قيمته ال

(0.05) و هو يصنف من النوع الممتاز [3].

\begin{tabular}{|c|c|c|c|c|c|c|c|c|c|}
\hline \multicolumn{10}{|c|}{ الجدول (5) قيم معامل الاختلاف المصنعي لجزاي الاراسة } \\
\hline \multicolumn{10}{|c|}{ الجزء الأول من البحث لارجات الحرارة المرتفعة والمنخفضة } \\
\hline \multicolumn{4}{|c|}{ التجارب الصيفية } & \multicolumn{6}{|c|}{ للتجارب الشتوية } \\
\hline \multicolumn{4}{|c|}{ التراكيز الملحية المستخدمة } & \multicolumn{5}{|c|}{ التراكيز الملحية المستخدمة } & \\
\hline 4000 & 1500 & 500 & 250 & 4000 & 1500 & 500 & 250 & & \\
\hline 0.010 & 0.016 & 0.018 & 0.016 & 0.026 & 0.016 & 0.013 & 0.019 & 0 & \\
\hline 0.020 & 0.032 & 0.019 & 0.012 & 0.025 & 0.017 & 0.014 & 0.009 & 500 & \\
\hline 0.017 & 0.017 & 0.032 & 0.014 & 0.021 & 0.011 & 0.025 & 0.009 & 1000 & \\
\hline 0.012 & 0.023 & 0.013 & 0.014 & 0.027 & 0.016 & 0.022 & 0.026 & 2000 & \\
\hline 0.016 & 0.026 & 0.018 & 0.008 & 0.017 & 0.006 & 0.022 & 0.020 & 4000 & $\frac{5}{k}$ \\
\hline \multicolumn{10}{|c|}{ الجزء الثاني من التجارب لمياه ذات التركيز الملحي 4000 ملفم/لتر } \\
\hline \multicolumn{10}{|c|}{ شدات المجال المغناطيسي المستخدمة } \\
\hline \multicolumn{2}{|c|}{4000} & \multicolumn{2}{|c|}{2000} & \multicolumn{2}{|c|}{1000} & \multicolumn{2}{|c|}{500} & \multicolumn{2}{|c|}{0} \\
\hline \multicolumn{2}{|c|}{0.015} & \multicolumn{2}{|c|}{0.018} & \multicolumn{2}{|c|}{0.025} & \multicolumn{2}{|c|}{0.019} & \multicolumn{2}{|c|}{0.026} \\
\hline
\end{tabular}

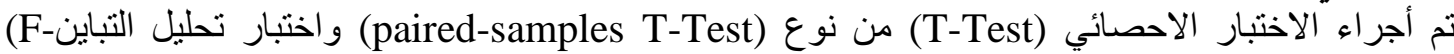

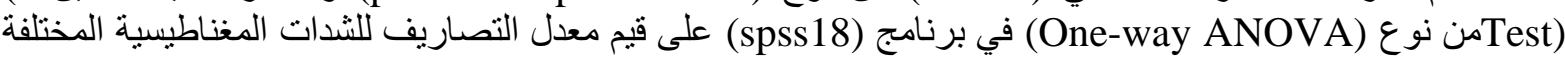


ومستويات الملوحة المختلفة المستخدمة للتجارب المنفذة خلال موسمي الصيف و الثتاء وتم اختيار دقة 95\% اي ان نسبة

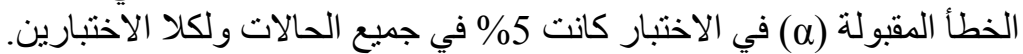

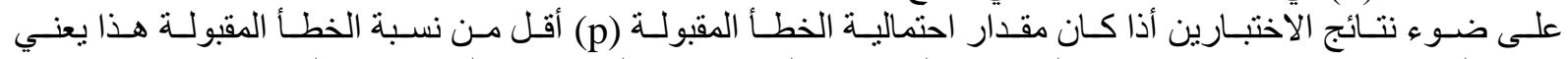

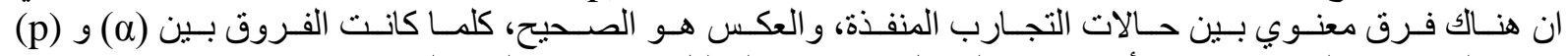

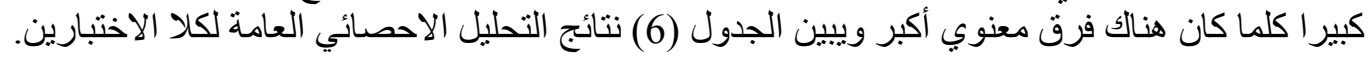

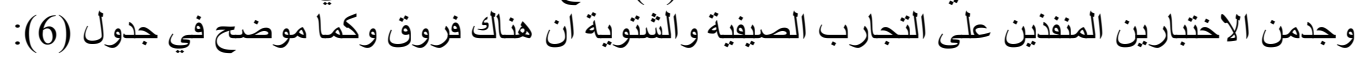

\begin{tabular}{|c|c|c|}
\hline \multicolumn{3}{|c|}{ الجدول (6) نتائج التحليل الاحصائي للتجارب المنفذة } \\
\hline تأثثير الملوحة على التصريف & تأثنير المجال المغناطيسي على التصريف & \\
\hline يوجد فرق معنوي & لا يو جد فرق معنوي & تجارب صيفية \\
\hline لايوجد فرق معنوي & يوجد فرق معنوي & ت تجارب شتوية \\
\hline
\end{tabular}

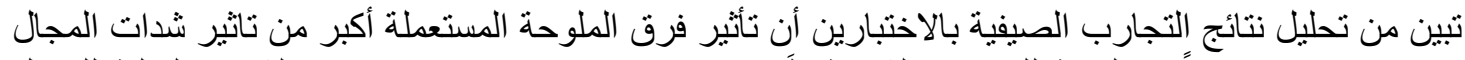

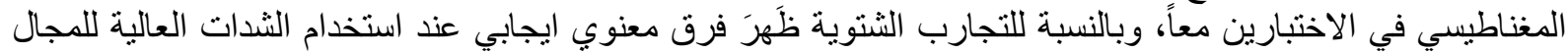

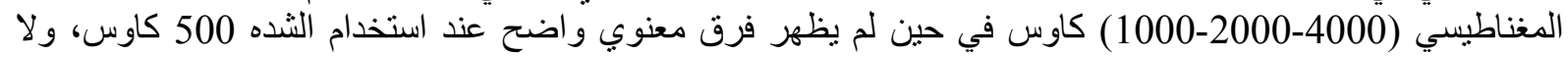
توجد فروق معنوية عند زيادة مستويات الملوحةٌ المستخدمة.

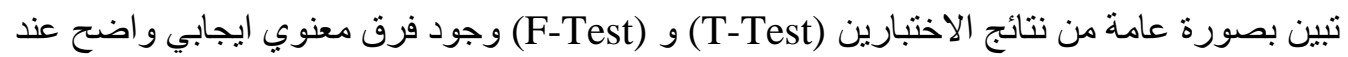

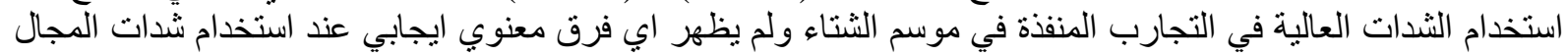
المغناطيسي المختلفة في التنجارب المنفذة في موسم الصيف الصنيف

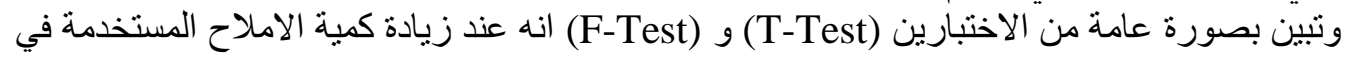

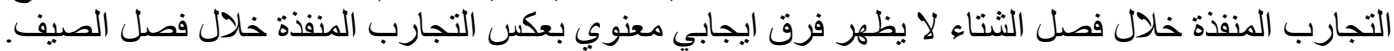

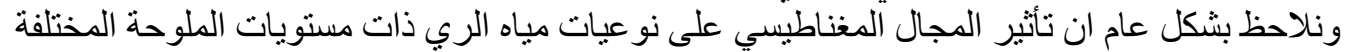
أفضل خلال موسم الثتاء مقارنة بنأثيره خلام ان موسم الصير الصيف.

1- هنالك تداخل بين تأثثر كل من درجة الحرارة والتغير ات المصنعية حالت دون معرفة التأثثر الدقيق لكل شدات

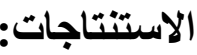
المجال المغناطيسي المستخدم.

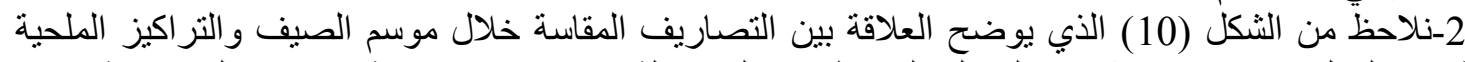

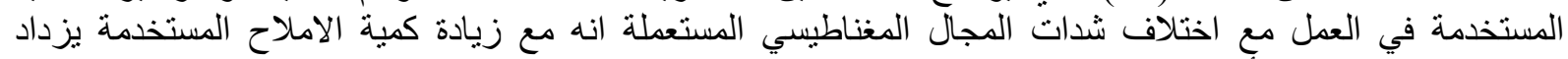

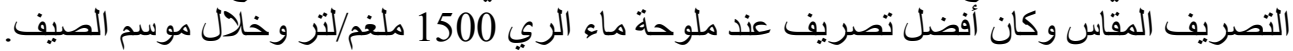

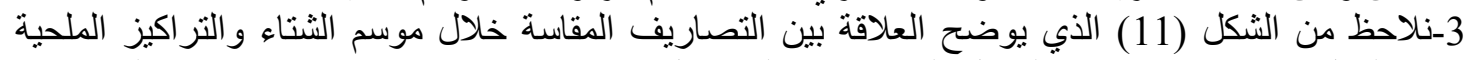

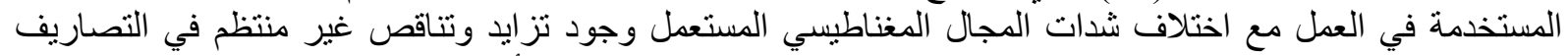

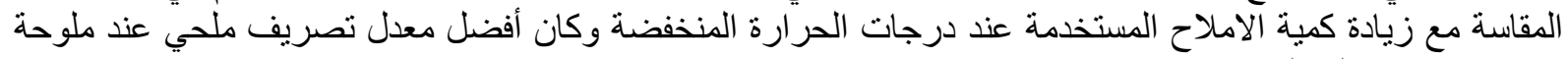

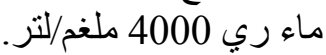

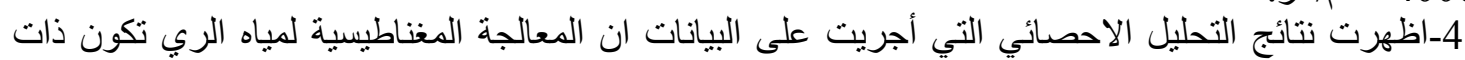

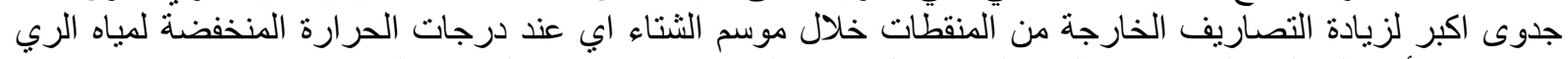

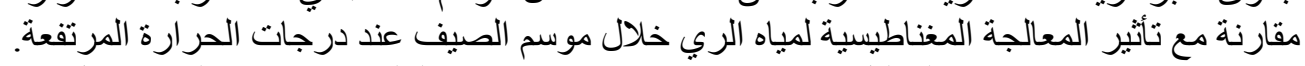

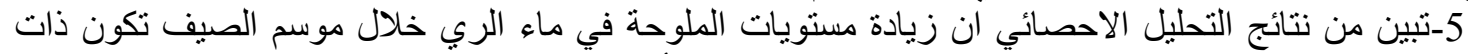

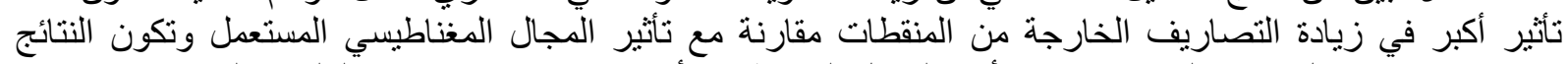

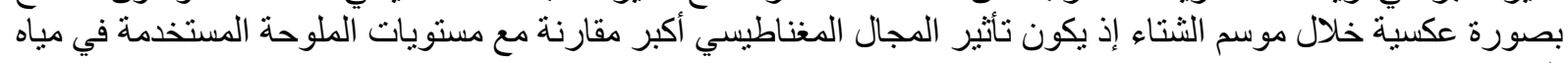


$\begin{array}{llll}\text { Al-Rafidain Engineering } & \text { Vol.22 } & \text { No. } 3 & \text { April } 2014\end{array}$

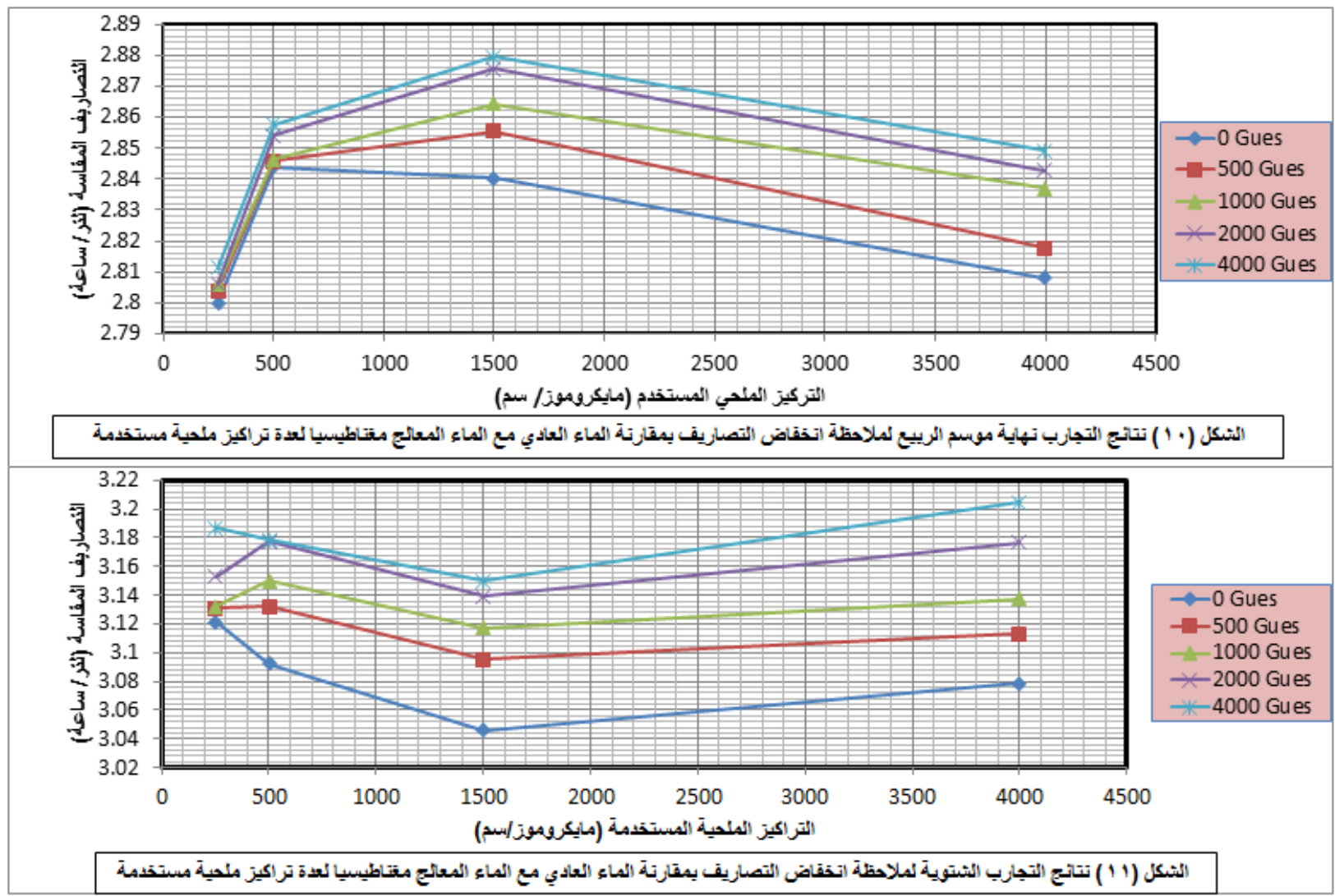

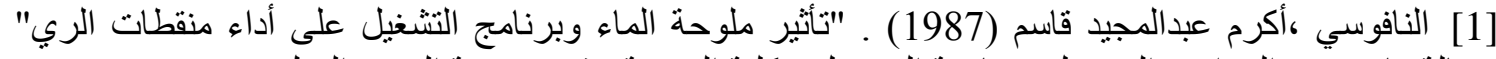

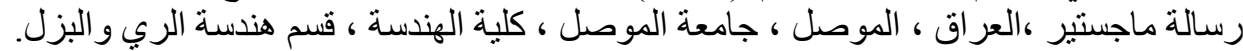

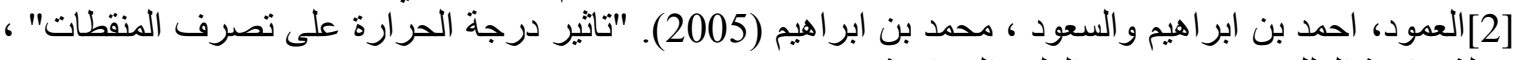

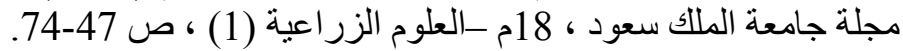
[3][حاجم، احمد يوسف، وحقي إسماعيل ياسين "الري الحقلي" دار الكتب للطباعة والنشر، جامعة الموصل، سنة

[4]شمشم ، سمير (2009). "تأثتير أستخدام مياه الري الممغنطة في نمو النبات ومحتواه من بعض العناصر

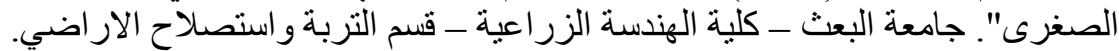

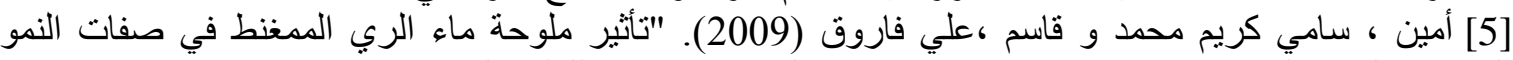

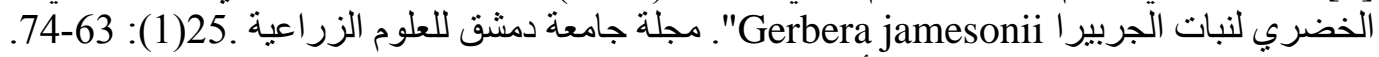

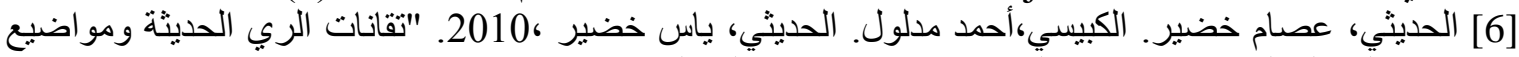

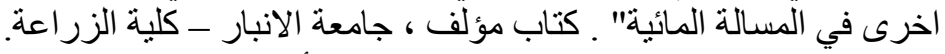

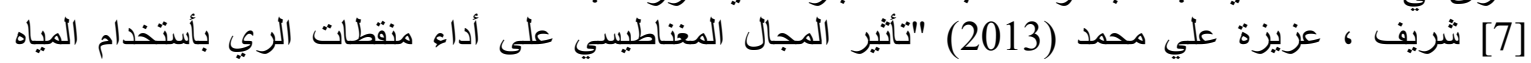
المالحة"،رسالة ماجستير ، كلية الهندسة، جامعة الموصل.

[8] Aali, K.A. \& Liaghat, A.M. \& Dehghanisanij, H. (2009). "The Effect of Acidification and Magnetic Field on Emitter Clogging under Saline Water Application”. Journal of Agricultural Science Vol.1,No.1.(www.ivsl.org)

[9] Fard, B.M. Khoshravesh, M., Mousavi,S.F. \& Kiani, A.R. (2011a). "Effect of Magnetized Water and Irrigation Water Salinity on Soil Moisture Distribution in Trickle Irrigation". Journal of irrigation and drainage engineering, ASCE/JUNE 2011/vol.137, issue 6. (www.ivsl.org) 
[10]Fard, B.M., Khoshravesh, M., Mousavi, S.F., \& Kiani, A.R. (2011b)."Effects of Magnetized Water on Soil Sulphate Ions in Trickle Irrigation". International Conference on Environmental Engineering and Applications. Vol. 17.(www.ivsl.org)

[11] Kaller, J. and Karmeli, D.,1975. "Trickle Irrigation Design". 1st ed. Rain Bird Sprinkler Mfg. Corp., Glendora,133 pp.

[12] Kronenberg, K. J.(2011).Magneto hydrodynamics: The effect of magnets oufluids GMX International (http://gmxinternational.com/facts/magneto.htm)

$$
\text { تم اجر اء البحت في كلية الهندسة - جامعة الموصل }
$$

